\title{
Determination and Correlation of the
}

\author{
Solubility of Cyproterone acetate in Fourteen
}

\author{
Pure Solvents and Water + Ethanol Mixed
}

\section{Solvents at Temperatures From 273.15 K to}

\section{$318.15 \mathrm{~K}$}

\section{Lifeng Ning ${ }^{1 \ddagger}$, Chengying Kuang ${ }^{2 \ddagger}$ and Juan $\mathrm{Xu}^{1 *}$}

${ }^{1}$ National Research Institute for Family Planning, Beijing 100081, People’s Republic of China

${ }^{2}$ Jiaozhou people's Hospital Of China, Qingdao 266300, People's Republic of China *Corresponding author. Tel:+86-010-62179135. Email address:xujuan@nrifp.org.cn

‡These authors contribute equally to this article.

Table of content:

Fig. S1. $\quad$ HPLC standard curve. 


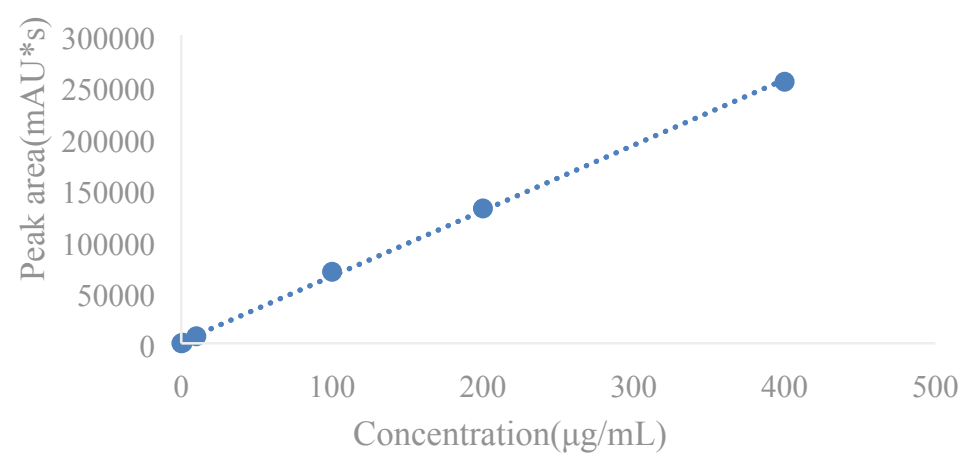

Fig. S1. HPLC standard curve. 